\title{
Application of Cooperative Learning Model of 'Two Stay-Two Stray (TSTS) Type on the Reaction Rate Material on the Students' Learning Outcomes in Class XI SMA Negeri 1 Banawa Tengah
}

\author{
*Alfiani, Irwan Said \& Vanny M. A. Tiwow \\ Pendidikan Kimia/FKIP - Universitas Tadulako, Palu - Indonesia 94119 \\ Received 17 December 2019, Revised 21 January 2019, Accepted 18 February 2020 \\ doi: 10.22487/j24775185.2020.v9.i1.pp40-46
}

\begin{abstract}
This study aimes to analipse the influence of students' learning outcomes on reaction rate by applying the cooperative learning model type TSTS (two stay-two stray) in class XI SMA Negeri 1 Banawa Tengah. The type of research was quasi-experimental (quasi-experimental research) with nonrandomized pretest-posttest control group design. This study was conducted on two classes, namely class XI IPA 1 as an experimental $(n=32)$ and class XI IPA 2 as the control class $(n=32)$. Analysis data used the two-party t-test statistical with the prerequisite test, namely normality and homogeneity test. The results showed that, the learning outcomes of students in the experimental class XI was 76.93 with a standard deviation $=8.62$ while in the control class X2 was 72.06 with a standard deviation $=8.53$. The results of hypothesis testing obtained - ttable $\leq$ tcount + ttable which was -1.67 $<3.25>+1.67$ with a significant level $(\alpha=0.05)$ and degrees of freedom $=62$. This showed that HO was rejected and HI was accepted it can be concluded that there is an effect of the application of the two stay-two stray (TSTS) type cooperative learning model on the reaction rate to the students' learning outcomes of class XI SMA Negeri 1 Banawa Tengah.
\end{abstract}

Keywords: Two stay-two stray (TSTS), students' learning outcomes, reaction rate

\section{Pendahuluan}

Salah satu kebijakan pembangunan pendidikan di Indonesia adalah peningkatan mutu pendidikan. Perbaikan pendidikan biasanya dimulai dari penataan isi kurikulum, hal ini dilakukan mengingat kurikulum merupakan komponen inti pendidikan yang dapat mempengaruhi komponen lainnya (Daryanto, 2009).

Pendidikan merupakan sebuah program yang saling melibatkan sejumlah komponen yang bekerja sama dalam sebuah proses untuk mencapai tujuan yang diprogramkan dengan membimbing individu menjadi seseorang yang dapat tumbuh dan berkembang dalam ilmu pengetahuan (Jumiah dkk., 2014). Pencapaian tujuan pendidikan nasional sebagaimana tercantum dalam UndangUndang Dasar 1945 maka digunakanlah kurikuklum yang berisi susunan serta pedoman pengajaran (Irdam dkk., 2014). Pendidikan mempunyai peranan penting bagi kelangsungan kehidupan manusia (Wahyuni dkk., 2015). Pendidikan memegang peranan penting dalam menjamin kelangsungan hidup suatu negara, karena pendidikan merupakan wahana untuk meningkatkan dan megembangkan kualitas Sumber Daya Manusia (SDM) (Sriwati dkk., 2015).
Guru merupakan salah satu faktor eksternal yang mempunyai peran penting untuk menunjang keberhasilan belajar siswa dalam proses pembelajaran di sekolah. Guru sebagai salah satu ujung tombak keberhasilan pendidikan hendaklah mampu berinovasi dalam mengembangkan pembelajaran yang dapat dijadikan motivasi dalam peningkatan hasil belajar (Yurefni dkk., 2015).

Keberhasilan proses pembelajaran tidak ter lepas dari kemampuan guru mengembangkan model-model pembelajaran yang berorientasi pada peningkatan kemampuan siswa secara efektif di dalam proses pembelajaran. Keragaman cara berfikir siswa merupakan keunikan tersendiri yang dimiliki masing-masing siswa (Ekawati, 2016).

Salah satu model pembelajaran yang berkembang saat ini adalah pembelajaran kooperatif. Pembelajaran ini menggunakan kelompok-kelompok kecil sehingga siswa-siswa saling bekerjasama untuk mencapai tujuan pembelajaran. Belajar kooperatif didasarkan pada hubungan antara motivasi, hubungan interpersonal, strategi pencapaian khusus, suatu ketegangan dalam individu memotivasi gerakan kearah pencapaian hasil yang di inginkan (Isjoni, 2009).

Bentuk pembelajaran yang dapat dilakukan adalah dengan menerapkan model pembelajaran yang inovatif (Yurneli dkk., 2015).

*Correspondence:

Alfiani

e-mail: guflinalfiani@gmail.com

(c) 2020 the Author(s) retain the copyright of this article. This article is published under the terms of the Creative Commons Attribution License 4.0, which permits unrestricted non-commercial use, distribution, and reproduction in any medium, provided the original work is properly cited. 
Pembelajaran kooperatif terdiri dari beberapa tipe yaitu, tipe team games tournamen (TGT), tipe two stay two ttray (TSTS), Snowball Throwing, Jigsaw dan lain-lain. Model pembelajaran yang baik adalah model yang dapat menciptakan proses belajar mengajar yang efektif dengan adanya komunikasi banyak arah. (Wardani dkk., 2014). Pendekatan two stay two stray merupakan model pembelajaran yang dapat melatih siswa berfikir kritis, kreatif dan efektif serta saling membantu memecahkan masalah dan saling mendorong untuk saling berprestasi dalam kelompoknya dan kelompok lain (Zulirfan dkk., 2009). Pembelajaran kooperatif tipe TSTS adalah adanya ketergantungan positif antara sesama peserta didik. Ketergantungan positif yang berarti bahwa tugas kelompok tidak mungkin bisa diselesaikan manakala ada kelompok yang tidak bisa menyelesaikannya dan semua ini memerlukan kerja sama baik antara anggota kelompok.

Pembelajaran two stay-two stray (TSTS) ju ga memiliki kelemahan kelemahan, salah satu kele mahannya yaitu dapat mengundang keributan ketika siswa bertamu ke kelompok lain dan penggunaan waktu yang kurang efektif dan memiliki kelebihan di antaranyakerjasama di dalam kelompok maupun di luar kelompok dalam proses belajar mengajar, kemampuan siswa dalam memberikan informasi kepada temannya yang lain di luar kelompok dan begitu juga sebaliknya ketika siswa balik ke dalam kelompoknya masing-masing (Kamala dkk., 2014).

Hasil wawancara yang dilakukan pada salah satu guru di SMA Negeri 1 Banawa Tengah khususnya kelas XI bahwa sebagian besar siswa masih sulit mempelajari dan memahami materi kimia sehingga hasil belajar yang diperoleh masih memiliki nilai standar terutama materi yang membutuhkan keterampilan matematika, misalnya pada materi Laju Reaksi khususnya pada perhitungan orde reaksi dan penentuan persamaan laju reaksi. Proses pembelajaran yang dilakukan masih menggunakan model pembelajaran konvensional yang berpusat pada guru. Proses pembelajaran ini siswa kurang respon (termotivasi) dalam mengembangkan diri dalam proses pembelajaran yang berakibat pada hasil belajar siswa yang kurang maksimal. Oleh karena itu, perlu adanya penerapan model pembelajaran untuk mengaktifkan dan mengembangkan potensi, cara berfikir dan aspek kepribadian siswa seperti kerja sama, bertanggung jawab, dan disiplin.

Adanya masalah tersebut maka peneliti ingin melakukan suatu proses pembelajaran yang efektif di dalam kelas untuk meningkatkan pemahaman konsep kimia. Selain itu, dalam pembelajaran juga perlu adanya interaksi antara siswa, agar siswa belajar lebih mudah, lebih aktif dalam proses pembelajaran di SMA Negeri 1 Banawa Tengah tersebut.

Tulisan ini dimaksudkan untuk mengidentifikasi adanya penerapan model pembelajaran kooperatif tipe TSTS (two stay-two stray) terhadap hasil belajar siswa pada materi Laju Reaksi pada kelas XI SMA Negeri 1 Banawa Tengah.

\section{Metode}

Pelaksanaan Penelitian ini di SMA Negeri 1 Banawa Tengah. Populasi dalam penelitian ini adalah seluruh kelas XI SMA Negeri 1 Banawa Tengah yang telah terdaftar pada tahun ajaran 2016/2017 yang berjumlah 62 orang siswa.Sampel dalam peneletian ini yaitu terdiri dari 32 siswa di kelas XI IPA 1 yang memiliki banyak siswa perempuan 23 dan siswa laki-laki 9 yang digunakan sebagai kelas eksperimen, kemudian 32 siswa kelas XI IPA 2, yang memiliki banyak siswa perempuan 24 dan siswa laki-laki 8 yang digunakan sebagai kelas kontrol. Pemilihan kelas yang menjadi sampel penelitian dilakukan melalui metode purposive sampling (berdasarkan pertimbangan bahwa kedua kelas tersebut memiliki kesamaan pada kondisi ruangan yang digunakan untuk belajar, waktu pembelajaran dan prestasi belajar kimia yang hampir sama)

\section{Tehnik Pengumpulan Data}

Data yang di perlukan dalam penelitian ini yaitu berupa hasil belajar siswa yang menggunakan model pembelajaran kooperatif tipe TSTS dengan langkah-langkah sebagai berikut : (1). Melakukan wawancara atau observasi di sekolah yang ingin dilakukan penelitian untuk mendapatkan berbagai informasi yaitu di SMA Negeri 1 Banawa Tengah; (2). Menyusun rencana pelaksanaan pembelajaran untuk kelas eksperimen dan kelas kontrol; (3). Menyusun instrument tes hasil belajar yang akan di uji untuk memperoleh informasi tentang hasil belajar siswa;(4).Melakukan kegiatan belajar mengajar dengan materi Laju Reaksi menggunakan model pembelajaran kooperatif tipe Two stay two stray (TSTS) untuk kelas eksperimen dan model pembelajaran konvensional untuk kelas control dengan jadwal yang telah disesuaikan; (5). Melakukan evaluasi pada akhir pembelajaran untuk mendapatkan data akhir dari proses pembelajaran kelas eksperimen maupun kelas kontrol.

\section{Instrumen Penelitian}

Instrumen yang digunakan dalam penelitian ini adalah: Rencana Pelaksanaan Pembelajaran (RPP) dan tes hasil belajar siswa berjumlah 14 soal yang merupakan soal materi laju reaksi yang berbentuk pilihan ganda. Dengan tipe soal pilihan ganda yang digunakan tes akhir untuk mengatahui perbedaan hasil belajar pada kelas eksperimen dan kelas kontrol. Melalui tes ini diharapkan dapat mengungkapkan bagaimana penguasaan siswa terhadap materi Laju Reaksi pada rana kognitif. 


\section{Teknik Analisis Data}

Teknik analisis data yang digunakan yaitu analisis instrumen, yang terdiri dari validitas soal, tingkat kesukaran tes, daya pembeda dan reabilitas tes. Validitas adalah suatu ukuran yang menunjukkan tingkat kevalidan atau kesahihan suatu instrument (Riduwan \& Sunarto, 2010). Kemudian analisis data hasil penelitian yang terdiri dari penilaian aktivitas siswa dan guru, pengujian $N$ Gain dan analisis inferensial. Analisis statistik inferensial digunakan untuk menguji hipotesis yang selanjutnya menarik kesimpulan tentang hasil belajar siswa.

Pengujian N-Gain dilakukan untuk melihat efektivitas pembelajaran dilihat dari peningkatan hasil pascatest (Hake, 2002).

\section{Hasil dan Pembahasan}

\section{Observasi Aktivitas Guru}

Untuk mencapai tujuan pendidikan dapat di lakukan melalui suatu proses. Proses yang di maksud dapat di tuangkan dalam pelaksanaan proses belajar mengajar baik di dalam kelas maupun di luar kelas (Lisdarika dkk., 2016). Kegiatan belajar dalam pendidikan formal tidak terlepas dari proses kegiatan belajar di sekolah. Agar proses pembelajaran berjalan dengan baik, maka seora ng guru selain menguasai materi pelajaran, dituntut juga menguasai model yang dapat mengaktifkan siswa dalam proses pembelajaran (Rahmawati, dkk 2015).

Data aktivitas guru diperoleh berdasarkan observasi yang dilakukan oleh seorang observer saat proses pembelajaran berlangsung baik di kelas eksperimen maupun kelas kontrol. Observasi dilakukan setiap pertemuan dengan menggunakan lembar observasi. Hasil observasi aktifitas guru dapat dilihat pada Tabel 1.

Tabel1. Hasil observasi aktivitas guru

\begin{tabular}{ccc}
\hline \multirow{2}{*}{ Pertemuan } & \multicolumn{2}{c}{ Persentase (\%) rata-rata guru } \\
& Kelas eksperimen & Kelas kontrol \\
\hline Pertemuan 1 & 76.47 & 73,33 \\
Pertemuan 2 & 80,88 & 76,66 \\
Pertemuan 3 & 85,29 & 80,00 \\
Pertemuan 4 & 86,74 & 86,66 \\
Rata-rata & 82,34 & 79,24 \\
\hline
\end{tabular}

Berdasarkan data yang terdapat pada Tabel 1 dapat dilihat aktivitas guru baik dalam pembelajaran pada kelas eksperimen maupun kelas kontrol termasuk dalam kategori kriteria baik.

\section{Observasi Aktivitas Siswa}

Data aktivitas siswa diperoleh melalui observasi yang dilakukan oleh seorang observer selama proses pembelajaran berlangsung baik pada kelas eksperimen maupun kelas kontrol. Observasi ini dilakukan setiap pertemuan dengan menggunakan lembar observasi. Hasil observasi aktivitas siswa dapat dilihat pada Tabel 2 .

Tabel 2. Hasil observasi aktivitas siswa

\begin{tabular}{lll} 
& & \\
& Kelas eksperimen & Kelas kontrol \\
\hline Pertemuan 1 & $79,68 \%$ & $70,58 \%$ \\
Pertemuan 2 & $84,37 \%$ & $86,76 \%$ \\
Pertemuan 3 & $81,25 \%$ & $88,23 \%$ \\
Pertemuan 4 & $98,43 \%$ & $82,35 \%$ \\
Rata-rata & $85,93 \%$ & $81.98 \%$ \\
\hline
\end{tabular}

Berdasarkan data pada tabel 2. diperoleh jumlah rata-rata persentase seluruh aktivitas siswa dengan menggunakan model pembelajaran kooperatif tipe Two Stay-Two Stray (TSTS) yaitu sebesar $85,93 \%$ sedangkan jumlah rata-rata persentase seluruh aktivitas siswa dengan menggunakan model pembelajaran Konvensional yaitu sebesar $81.98 \%$. Hasil rata-rata persentase yang diperoleh menunjukkan aktivitas siswa di dalam kelas eksperimen dan kelas kontrol termasuk kriteria baik.

\section{Analisis Hasil Belajar Siswa}

Analisis hasil belajar siswa terbagi atas analisis hasil belajar siswa pada tes awal (Pretest) dan analisis hasil belajar siswa pada tes akhir (Postest). Instrumen yang digunakan untuk mengukur hasil belajar siswa adalah instrument tes yang telah ditentukan validitasnya baik secara teoritis maupun empiris. Berdasarkan hasil validitas tersebut dari 26 soal yang diujicobakan diperoleh 14 soal yang dinyatakan valid atau dapat digunakan untuk mengukur hasil belajar siswa dengan nilai rata-rata 
validitas sebesar 0.43 dan nilai reliabilitas sebesar 1.019 Sehingga dapat dijadikan tes baku dan digunakan untuk pretest dan postest.

\section{Analisis Hasil Tes Awal Siswa (Pretest)}

Tes kemampuan awal siswa dilakukan untuk mengetahui kemampuan awal siswa.baik kelas kontrol maupun kelas eksperimen sebelum dilaksanakan pembelajaran dengan materi laju reaksi. Hasil tes kemampuan awal siswa kelas kontrol diperoleh nilai rata-rata 6.03 dan untuk kelas eksperimen diperolah nilai rata-rata 6.46.

Nilai rata-rata pretest yang diperolah dikelas eksperimen lebih tinggi dari pada kelas
kontrol.Tetapi perbedaanya tidak terlalu signifikan. Hal ini berarti bahwa kemampuan awal siswa kelas kontrol dan kelas eksperimen hampir sama.

\section{Analisis Hasil Tes Akhir Siswa (Postest)}

Tes Kemampuan akhir siswa dilakukan untuk melihat hasil belajar siswa setelah dilakukan pembelajaran materi laju reaksi dengan menerapkan model kooperatif tipe Two Stay-Two Stray pada kelas eksperimen dan model Konvensional pada kelas kontrol.Data posttes hasil belajar siswa yang telah dianalisis disajikan pada Tabel 3 .

Tabel 3. Hasil analisis data postest pada kelas eksperimen dan kelas kontrol.

\begin{tabular}{lll}
\hline \multirow{2}{*}{ Uraian } & Tes Kemampuan Akhir (Postest) & \\
& Kelas Eksperimen & Kelas Kontrol \\
\hline Sampel & 32 & 32 \\
Nilai Terendah & 64 & 57 \\
Nilai Tertinggi & 93 & 92 \\
Nilai rata-rata & 76.93 & 72.06 \\
\hline
\end{tabular}

Data yang terdapat pada tabel 3 menunjukkan bahwa penerapan model pembelajaran kooperatif tipe Two Stay Two Stray (TSTS) dapat mempengaruhi hasil belajar siswa dengan melihat nilai rata posttest yang lebih tinggi pada kelas eksperimen dibandingkan dengan kelas kontrol.

\section{N-Gain Hasil Belajar Siswa}

Perhitungan $\mathrm{N}$-gain dilakukan dengan tujuan untuk mengetahui keefektifan model pembelajaran yang diterapkan baik pada kelas kontrol maupun kelas eksperimen dengan melihat peningkatan hasil belajar siswa pada tes awal (pretest) dan tes akhir siswa (posttest). Hasil perhitungan $\mathrm{N}$-gain dapat dilihat pada Tabel 4.

Tabel 4. Hasil nilai pengujian N-Gain dalam persentase(\%)

\begin{tabular}{lllll}
\hline \multirow{2}{*}{ Kelas } & \multicolumn{4}{l}{ Kriteria Indeks Gain } \\
& Jumlah sampel & Tinggi (\%) & Sedang (\%) & Rendah (\%) \\
\hline Eksperimen & 32 & 83.59 & 58.4 & 0 \\
Kontrol & 32 & 78.2 & 61.47 & 0 \\
\hline
\end{tabular}

Data yang terdapat pada tabel diatas menunjukkan bahwa rata-rata $\mathrm{N}$-gain dalam persentase (\%) yang diperoleh dari kelas eksperimen dan kelas control termasuk dalam kategori tinggi dan sedang. Persentase (\%) kriteria N-gain dari kelas eksperimen diperoleh nilai $\mathrm{N}$-gain lebih tinggi dibandingkan dengan kelas control dengan menunjukkan bahwa model pembelajaran kooperatif tipe two stay-two stray (TSTS) yang diterapkan pada kelas eksperimen lebih baik dibandingkan kelas kontol.

\section{Pengujian Hipotesis}

Pengujian hipotesis adala untuk membandingkan (membedakan) hasil belajar siswa menggunakan model pembelajaran kooperatif tipe two stay-two stray (TSTS) dan model pembelajaran Konvensional Kriteria pengujiannya adalah jika $t_{\text {tabel }} \leq t_{\text {thitung }} \leq+t_{\text {tabel }}$ maka $\mathrm{H}_{0}$ diterima dan $\mathrm{H}_{\mathrm{a}}$ ditolak pada Harga $\mathrm{t}_{(0.95)}$ dengan derajat kebebasan, $\mathrm{dk}=62$. Berdasarkan hasil yang diperoleh $-\mathrm{t}_{\text {tabel }}<$ $t_{\text {hitung }}>+t_{\text {tabel }},(-1,68<3,25>+1,68)$, maka $\mathrm{H}_{0}$ ditolak dan $\mathrm{H}_{\mathrm{a}}$ diterima, sehingga dapat disimpulkan bahwa terdapat pengaruh penerapan model pembelajaran kooperatif tipe two stay-two stray (TSTS) terhadap hasil belajar siswa pada materi Laju Reaksi.

Penelitian ini dilakukan untuk mengetahui informasi tentang pengaruh penerapan model pembelajaran kooperatif tipe Two Stay-Two Stray pada materi Laju Reaksi kelas XI di SMA Negeri 1 Banawa Tengah.Objek yang digunakan pada penelitian ini yaitu siswa kelas XI IPA 1 dan IPA 2 yang terdiri dari masingmasing siswa sebanyak 32 siswa. Siswa kelas IPA 1 dikategorikan sebagai kelas eksperimen dan siswa kelas IPA 2 sebagai kelas kontrol, siswa kelas eksperimen diberikan model pemebelajaran two stay-two stray (TSTS) dan siswa kelas kontrol diberikan model pembelajaran konvensional. Kedua kelas tersebut diberikan materi pembelajarn yang sama dan jumlah jam pelajaran yang sama yaitu 12 jam pelajaran sebanyak 4 kali pertemuan. Sebelum melaksanakan kegiatan 
pembelajaran, kedua kelas tersebut diberikan perlakuan tes awal (pretest) dengan tujuan untuk mengetahui pengetahuan awal dari siswa dan juga mengukur kemampuan siswa dalam pemahaman materi yang disampaikan. Berdasarkan hasil pretest yang diperoleh mempunyai nilai rata-rata hasil belajar siswa yaitu kelas XI IPA 1 sebesar 6.46 dan nilai rata-rata kelas XI IPA 2 sebesar 6.03. Ini menunjukkan bahwa kemampuan awal siswa dari kedua kelas hampir sama dalam mengenal materi yang di uji cobakan. Setelah melaksanakan proses pembelajaran sesuai dengan RPP, diakhir pembelajaran siswa diberikan tes hasil belajar. Tes hasil belajar siswa berupa soal pilihan ganda yang berjumlah 14 butir soal yang sudah tervalidasi yang diberikan sesudah pembelajaran (posttest). Posttest bertujuan untuk melihat bagaimana pengaruh model pembelajaran kooperatif tipe two stay-two stray (TSTS) terhadap hasil belajar siswa pada materi Laju Reaksi.

Berdasarkan hasil penelitian yang telah diperoleh dari kedua kelas untuk analisis statistik deskriptif dengan menggunakan nilai rata-rata untuk melihat atau menunjukkan sejauh mana pemahaman siswa yang diterapkan kepada kedua kelas, maka hasil yang diperoleh nilai rata-rata kelas eksperimen yang diberi perlakuan TSTS lebih tinggi dibandingkan kelas kontrol seperti yang disajikan dalam Tabel 3.

Berdasarkan Tabel 3 bahwa nilai rata-rata kelas eksperimen lebih tinggi dengan jumlah nilai 76.93 dan pada kelas kontrol dengan jumlah nilai 72.06. Data tersebut dapat dilihat bahwa model pembelajan kooperatif tipe TSTS dapat mempengaruhi proses belajar mengajar di sebabkan ketertarikan siswa dalam pelaksanaan model pembelajaran yang membuat mereka menjadi aktif, kreatif dan bertanggung jawab dalam mengemukakan pendapat, dan juga melatih mereka dalam berbicara didepan kelas bersama teman-teman siswa lainnya serta melatih mereka dalam memberikan pertanyaan dan jawaban kepada teman kelompok maupun yang lainnya, mereka lebih mudah memahami soal yang diberikan, berani dalam menyampaikan apa yang mereka sudah kerjakan di depan guru dan siswa lainnya. Dalam pembelajaran kooperatif tipe TSTS akan ditemukan suasana yang positif, dimana siswa dapat dengan bebas berinteraksi dengan siswa lainnya dan dapat membangun semangat kerja sama (Putri dkk., 2016).

Dari tabel tersebut, maka dapat disimpulkan bahwa pembelajaran dengan menggunakan model TSTS berpengaruh terhadap hasil belajar siswa kelas XI IPA 1 SMA Negeri 1 Banawa Tengah. Bukan hanya nilai rata-rata yang menunjukan jika model pembelajaran TSTS berpengaruh terhadap hasil belajar siswa, pengujian dengan $\mathrm{N}$-Gain juga menunjukan bahwa keefektivitas model pembelajaran TSTS lebih tinggi daripada kelas kontrol seperti yang ditunjukan dalam Tabel 4. Berdasarkan tabel tersebut dapat dilihat nilai N-Gain yang diperoleh dari kelas eksperimen yaitu indeks gain kriteria tinggi sebesar $83.59 \%$ dan indeks kriteria sedang sebesar 58.4\% sedangkan perolehan dari kelas kontrol yaitu indeks gain kriteria tinggi sebesar $78.2 \%$ dan indeks gain kriteria sedang sebesar $61.47 \%$. Jadi dapat disimpulkan bahwa indeks gain atau N-Gain kelas eksperimen yang menggunakan model pembelajaran TSTS lebih tinggi daripada kelas kontrol. Penggunaan model pembelajaran yang tepat dapat mendorong tumbuhnya rasa senang siswa terhadap pelajaran, menumbuhkan dan meningkatkan motivasi dalam mengerjakan tugas, memberikan kemudahan bagi siswa untuk memahami pelajaran sehingga memungkinkan siswa mencapai hasil belajar yang lebih baik (Aunurahman 2009).

Selain penilaian dengan memberikan tes soal pilihan ganda, adapun penilaian proses belajar mengajar yang di tinjau oleh observer, yaitu observer terhadap guru dan observer terhadap siswa, dengan melihat aktivas yang dilakukan oleh guru dan siswa selama proses pembelajaran dalam empat kali pertemuan di kelas eksperimen maupun kelas konrol, untuk penilaian aktivitas guru pada kelas eksperimen dan kelas kontrol hampir sama. Guru berperan dengan aktif dalam kegiatan belajar mengajar. Hasil dari pendidikan dan pengajaran sangat ditentukan oleh apa yang terjadi di kelas. Oleh sebab itu sudah pasti kelas harus dikelolah dengan profesional (Mahyuni \& Wayan 2015). Bukan hanya pada aktivitas guru, aktivitas siswa pun di nilai oleh observer dilihat pada Tabel 1 hasil observasi aktivitas siswa dengan menggunakan model pembelajaran Konvensional yaitu sebesar 81.98\%. Hasil rata-rata persentase yang diperoleh menunjukkan aktivitas siswa di dalam kelas eksperimen dan kelas kontrol termasuk kriteria baik. Zaini dkk., (2011) menyatakan bahwa siswa yang aktif dalam belajar, pengetahuan yang diterima siswa akan lebih lama diingat sehingga hasil belajar menjadi lebih baik. Jadi, siswa yang aktif dalam proses belajar akan memperoleh prestasi belajar yang baik.

Berdasarkan hasil penelitian yang di lakukan di SMA Negeri 1 Banawa Tengah baik itu melalui pengujian hipotesis, homogenitas, Normalitas dan nilai skor rata- rata dan uji N-Gain bahwa dengan menerapkan model pembelajaran Two Stay-Two Stray (TSTS) pada materi kimia khususnya laju reaksi dapat mempengaruhi hasil belajar siswa dan bisa diterapkan di sekoalh tersebut dan bukan hanya pada mata pelajaran kimia . mata pelajaran lain pun bisa di terapkan model pembelajaran Two Stay-Two Stray (TSTS).

\section{Kesimpulan}

Penerapan model pembelajaran tipe Two Stay-Two Stary (TSTS) terhadap hasil belajar siswa 
pada materi Laju Reaksi di kelas XI IPA dapat memberikan hasil yang lebih baik di bandingkan kelas XI IPA 2 yang menggunakan model pembelajaran Konvensional di SMA Negeri 1 Banawa Tengah.

\section{Ucapan Terima kasih}

Penulis mengucapkan terima kasih kepada Abdul Hafid selaku kepala SMA Negeri 1 Banawa Tengah, Nikmawati selaku guru kimia di SMA Negeri 1 Banawa Tengah, seluruh siswa kelas XI SMA Negeri 1 Banawa Tengah, dan seluruh pihak yang telah membantu penulis dalam menyelesaikan penelitian ini.

\section{Referensi}

Aunurrahman. (2009). Belajar dan pembelajaran. Bandung: Alfabeta.

Daryanto. (2009). Panduan proses pembelajaran. Jakarta: AV Publisher.

Ekawati, H. (2016) Perbedaan penerapan model pembelajaran kooperatif antara tipe think pair share (tps) dan tipe two stay two stray (tsts) berdasarkan gaya kognitif siswa. Jurnal Pendidikan Mahakam, 1(2), 165-177.

Firmantara, B., Armis., \& Siregar, S, N. Penerapan model pembelajaran kooperatif tipetwo stay two stray (tsts) untuk meningkatkan hasil belajar matematika peserta didik kelas viii smp negeri 11 pekanbaru. Jurnal Bidang Keguruan dan Ilmu Pendidikan, 3(2), 113.

Hake. R. R. (2002). Assessment of student learning

inintroductory science course. [Online]

. Tersedia: https://pdfs.semanticscholar. org/3280/87bfbf4d36e3aac9f04f3e1f36 2a2e9ed410.pdf [20 November 2017].

Irdam., Idrus,. \& Zukmadini, A, Y. (2014). Penerapan model pembelajaran kooperatif tipe two stay two stray (tsts) sebagai upaya meningkatkan aktifitas dan hasil belajar biologi siswa kelas viii b smp negeri 22 kota bengkulu. Jurnal Pendidikan Biologi, 11(1), 21-185.

Isjoni. (2009). Pembelajaran kooperatif. Yogyakarta: Pustaka Pelajar.

Jumiah., Erlisnawati., \& Hamizih. (2014). Penerapan model pembelajaran kooperatif tipe two stay two stray (tsts) untuk meningkatkan hasil belajar ips siswa kelas iv sdn 028 sintong kecamatan tanah putih kabupaten rokan hilir. Jurnal Pendidikan Dasar, 1(2), 1-20.

Kamala, M., Risdawati, R., \& Sari, L.Y.(2014). Penerapan model pembelajaran kooperatif tipe two stay two stray (tsts) terhadap hasil pembelajaran biologi kelas x sman 2 koto baru kabupaten dharmasraya. Jurnal STKIP PGRI Sumbar, 4(2), 1-4.

Lisdarika., Indrawati, H., \& Haryana, G. (2016). Penerapan model pembelajaran kooperatif tipe two stay two stray (tsts) untuk meningkatkan hasil belajar ips siswa kelas viii 2 smp negeri 3 tanah putih kabupaten rokan hilir. Jurnal Bidang Keguruan dan Ilmu Pendidikan, 3(2), 112.

Mahyuni, S., \& Wayan, N. (2013) Pengaruh penerapan model pembelajaran kooperatif tipe two stay two stray (tsts) terhadap hasil belajar kimia kelas xi ipa sma negeri 1 selemadeg ditinjau dari gaya berpikir. Jurnal Administrasi Pendidikan, 4(1), 1-13.

Putri, H., Zulkarnain., \& Yuanita, P.(2015). Penerapan model pembelajaran kooperatif tipe tsts untuk meningkatkan hasil belajar matematika peserta didik kelas viii. 2 smpn 3 bangkinang. Jurnal Bidang Keguruan dan Ilmu Pendidikan, 2(2), 1-13.

Rahmawati., Resmiwetti., \& Rini. (2015). Penerapan model pembelajaran tipe two stay two stray (tsts) untuk meningkatkan prestasi belajar siswa pada pokok bahasan struktur atom dan sistem periodik unsur di kelas $\mathrm{x}$ sma negeri 2 tambang. Jurnal Pendidikan Kimia, 2(1), 1-9.

Riduwan, \& Sunarto. (2010). Dasar-dasar statistika. Bandung: Alfabeta.

Sriwati., Lazim, N., \& Zulkifli. (2015). Penerapan model pembelajaran kooperatif tipe two stay two stray (tsts) untuk meningkatkan hasil belajar ips siswa kelas iv sd negeri 007 sungai kubu kecamatan kubu kabupaten rokan hilir. Jurnal Bidang Keguruan dan Ilmu Pendidikan, 2(1), 111.

Wahyuni, D., Syahrilfuddin., \& Antosa, Z. (2015). Penerapan model pembelajaran kooperatif tipe two stay two stray (tsts) untuk meningkatkan hasil belajar matematika siswa kelas iv sd negeri 001 bagan kota bagansiapiapi. Bidang Keguruan dan Ilmu pendidikan, 2(1), 112.

Wardani, E, P., Gunowibowo, P., \& Nurhanurawati (2014). Penerapan 
Model Pembelajaran Kooperatif Tipe TSTS untuk Meningkatkan

Kemampuan Komunikasi Matematis

Siswa. Jurnal Pendidikan Matematika, 2(5), 1-7.

Yurefni, Munjiatun, \& Alpusari, M. (2015).

Penerapan model pembelajaran kooperatif tipe two stay two stray(tsts) untuk meningkatkan belajar hasil ipa siswa kelas iv a sdn 022 jayamukti dumai. Jurnal Pendidikan Dasar, 2(1), 1-13.

Yurneli,. Daud, D., Syahrilfuddin. (2015). Penerapan model pembelajaran kooperatif tipe two stay two stray (tsts) untuk meningkatkan hasil belajar ipa siswa kelas IV SDN 005 sungai pinang kecamatan Kubu kabupaten Rokan Hilir. Jurnal Bidang Keguruan dan Ilmu pendidikan, 2(1), 1-14.

Zaini, H., Munthe, B., \& Aryani, S, A. (2011). Strategi pembelajaran. Yogyakarta: CTSD.

Zulirfan., Diana., \& Irianti, M. (2009). Hasil belajar keterampilan psikomotor fisika melalui penerapan model pembelajaran kooperatif tps dan tsts pada siswa kelas x ma darel hikmah pekanbaru. Jurnal Geliga Sains, 3(1), 43-47. 